Check for updates

The BMJ

Cite this as: BMJ 2021;373:n1654 http://dx.doi.org/10.1136/bmj.n1654 Published: 28 June 2021

\title{
Covid-19: GPs urge government to clear up confusion over symptoms
}

\section{Elisabeth Mahase}

GPs have called on the government to update the official list of covid-19 symptoms after seeing patients shun tests to check their infection status because they don't believe they have been infected by SARS-CoV-2. They also said that a public communication campaign was needed to inform the public about the limitations of lateral flow tests and vaccination.

The website of the Covid Symptoms Study being run by the health science company ZOE and King's College London said the most commonly reported covid-19 symptoms were now headache, runny nose, and sore throat and not fever, cough, and loss of sense of smell or taste, as listed by the government. ${ }^{1}$

Lack of information about this changing profile of symptoms is making dealing with patients difficult and could thwart efforts to control the pandemic, GPs have told The BMJ.

The Cumbria GP Ellen Welch said, "I work entirely remotely, both in and out of hours, and the vast majority of people contacting out-of-hours services with coughs or fevers still express surprise and frustration when a covid-19 test is mentioned. People 'know' it's not covid-19.

"If we end up referring people on for face-to-face appointments via out-of-hours [services] or NHS 111 we ask the standard covid questions about any symptoms, and I would say almost every single person responds to the 'do you have any covid-19 symptoms' question ... with, 'Oh, I've had both my vaccinations,' as if this means it doesn't apply to them any more."

The Nottinghamshire GP Prakash Kachhala said, “I'm struggling to recall anyone I have spoken to at an urgent appointment having done or arranged a PCR test. We saw this even before delta with straightforward coughs and fevers, but obviously it's more complex with delta and broader symptoms. While access to testing is much better than last year, it seems that fewer people who contact the GP are doing it. Lateral flow tests don't help, and I wonder if access to them is reducing those going for PCR."

Lateral flow tests, which are now available to the public for twice weekly testing, are supposed to be used to identify asymptomatic cases. This means that a negative result does not rule out infection. However, the communication about the use of these tests has been poor. A BMJ investigation found that only one third of local authorities that rolled out these tests made their limitations clear to the public. ${ }^{2}$

The Hertfordshire GP Neena Jha also said she had seen such problems at her practice. "I don't think the blame is with the patients at all. I think it's poor public health messaging, and patients have misunderstood the role of the lateral flow tests and what the results mean.”
However, Jha said that some patients became angry when they were advised to get a PCR test. "I think there is this backlog of frustration and misunderstanding," she said, "which I think has been driven by some of the media outlets that have [spread] this rhetoric that GPs have been closed and we're using covid-19 as an excuse not to see patients, which couldn't be further from the truth.

“We set up covid community hot sites, we've been seeing covid and non-covid [patients] face to face throughout. There has just been a tele- or remote appointment first [policy], and that was at the direction of NHS England. But the way it's been spun has been really damaging. And we've seen a huge increase in aggression from patients since then.”

GPs now want to see a public communication campaign, led by the government, to tackle these misunderstandings around symptoms, testing, and vaccination.

Martin Marshall, chair of the Royal College of General Practitioners, said, "With the delta variant, patients are presenting with symptoms more commonly associated with colds and flu, such as a sore throat, runny nose, and fever.

"It's vital that public health information about covid-19 and advice for patients on how to behave-including appropriate ways to seek help-if they have symptoms continues to be prominent and is kept up to date as our understanding about the virus changes."

The Department of Health and Social Care for England was approached for comment but had not responded at the time of publication.

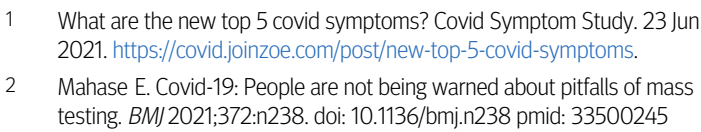

2 Mahase E. Covid-19: People are not being warned about pitfalls of mass testing. BMJ2021;372:n238. doi: 10.1136/bmj.n238 pmid: 33500245

This article is made freely available for use in accordance with BMJ's website terms and conditions for the duration of the covid-19 pandemic or until otherwise determined by BMJ. You may use, download and print the article for any lawful, non-commercial purpose (including text and data mining) provided that all copyright notices and trade marks are retained. 